\title{
Animating a Curriculum Framework Through Educator Co-Inquiry: Co-Learning, Co-Researching, and Co-Imagining Possibilities
}

\author{
Jane Hewes, Patricia Lirette, Lee Makovichuk, and Rebekah McCarron
}

\begin{abstract}
Dr. Jane Hewes is associate dean and associate professor in the Faculty of Education and Social Work at Thompson Rivers University. As co-principal investigator on the research team that is writing and developing Play, Participation, and Possibilities: An Early Learning and Child Care Curriculum Framework for Alberta, she brings expertise in participatory research methodologies, interest in critical, postfoundational early years' pedagogies, and a commitment to valuing the knowledge that childcare educators bring to professional learning. Email: jhewes@tru.ca
\end{abstract}

Dr. Tricia Lirette is a long-time faculty member in the early learning and child care diploma program at MacEwan University and currently holds the position of department chair of human services and early learning. She is co-principal investigator on the research team that is developing the Alberta curriculum framework. Her other research interests include child and family policy and applying the lens of institutional ethnography to inquiry in ELCC.

Lee Makovichuk, MEd, is assistant professor with the department of Human Services and Early Learning at MacEwan University. Her work as a co-writer and co-researcher of Play, Participation, and Possibilities: An Early Learning and Child Care Curriculum Framework for Alberta and pedagogical mentoring work with early childhood educators has been inspiration for her doctoral studies.

Rebekah McCarron graduated from the MacEwan University early learning and child care diploma program in 2014. As an educator at the University Child Care Centre Society in Calgary, Alberta, she works with a group of kindergarten-aged children and their families. Together, they have been exploring the theories of physics using loose parts (including large loose parts outside).

The shift toward a pedagogical foundation for professional practice in early childhood along with the introduction of curriculum frameworks in early learning and child care, calls for approaches to professional learning that move beyond transmission modes of learning towards engaged, localized, participatory models that encourage critical reflection and investigation of pedagogy within specific settings. In this paper, we describe ongoing participatory research that explores educator co-inquiry as an approach to animating a curriculum framework. A story of curriculum meaning making that opened a hopeful space for critical pedagogical reflection and changed practice serves as a basis for deeper reflection.

Key words: professional learning; pedagogical dialogue; early childhood care and education; coinquiry; curriculum framework

dialogic, participatory process of documenting curriculum meaning making in action brought with it great hopefulness and the possibility that academics and early childhood educators might create a "pedagogical meeting
In 2012, the government of Alberta, inspired by the ground-breaking work in New Brunswick, invited researchers at MacEwan University in Edmonton and Mount Royal University in Calgary to create an early learning and child care (ELCC) curriculum framework. The framework was intended to guide the everyday practice of early childhood educators working with children from newborns to age 5 in centre-based child care and family day home programs. Leading the development of the framework, the research team at MacEwan University began with the understanding that early childhood curriculum is shaped by the pedagogic decisions educators make on the ground and in the moment, and focused on broad holistic goals rather than the delivery of predetermined content (Bennett, 2004). We knew that engaging practicing educators in co-creating the framework would be critical to its relevance to the field and its success over time. Taking up the methodology of participatory action research (MacNaughton \& Hughes, 2008, p. 154), we invited over 50 educators in four local early childhood programs to co-author stories of teaching and learning (Carr, 2001)
to include as sample narratives in the framework. This co-author stories of teaching and learning (Carr, 2001)
to include as sample narratives in the framework. This 
place" (Moss, 2013), going forward together as co-learners, co-researchers, and co-imaginers of curriculum meaningmaking possibilities.

Play, Participation and Possibilities: An Early Learning and Child Care Curriculum Framework for Alberta ${ }^{1}$ took shape over two years and is organized around five core concepts, four broad holistic goals, and five dispositions to learn, as shown in Figure 1. The image of the child as a mighty learner emerged in the process of co-creating the framework and captured the imaginations of educators, families, and policy makers alike.

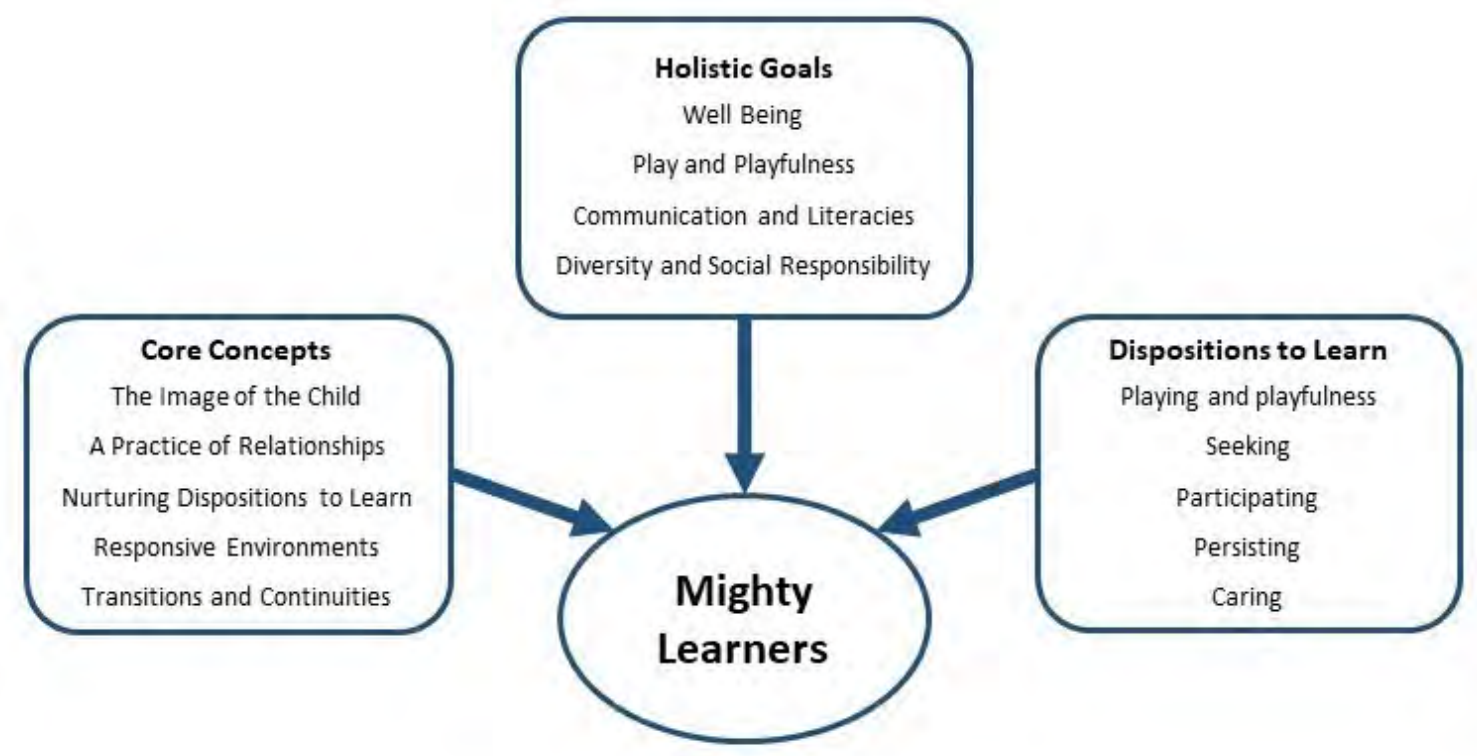

Figure 1. Play, Participation, and Possibilities.

The framework is firmly grounded in sociocultural pedagogies and gestures toward the postfoundational, introducing notions of equity, social justice, gender, and diversity. Following the initial development, multi-year government funding (2012-present) afforded an incredible opportunity to explore the process of animating the curriculum framework in everyday practice, with the active participation of educators alongside researchers. The holistic goal of well-being-focused on nurturing emotional health and positive identities, creating a sense of belonging, and promoting physical health-was an entry point for many educators working with the curriculum for the first time, and it features in the story of curriculum meaning making in this paper.

Building on international scholarship about professional learning in early childhood education and care (Edwards \& Nuttall, 2009; Eurofound, 2015; Pacini-Ketchabaw, Kocher, Sanchez, \& Chan, 2009), we searched for theoretical frameworks that moved beyond transmission modes of learning toward engaged, localized, participatory models that encourage critical reflection and investigation of pedagogy within specific settings (Patterson, McAuley, \& Fleet, 2013). Using pedagogical documentation as a provocation to question, challenge, validate, and theorize practice, we engaged with participating educators in co-inquiry processes (Perry, Henderson, \& Meier, 2012) to deepen and complexify thinking about co-constructing curriculum in the here and now with young children and their families.

In this paper, we describe co-inquiry as a strategy for animating early childhood educators' use of Play, Participation, and Possibilities in curriculum planning and meaning making, for creating supportive social contexts for pedagogical 
conversations that invite multiple and diverse perspectives, and for considering critically and thoughtfully what it means for families to be meaningfully engaged in children's learning. Valuing the notions that educational theory is embedded in and emerges from educational practice and that curriculum is already happening in early childhood programs, our intent, as researchers and educators, is to explore processes of professional learning that theorize practice and deepen understanding of early learning pedagogy, using the common language of [curriculum framework]. We draw inspiration from Marg Sellers' (2013) notion of children "curriculuming" and Liselotte Olsson's (2009) view that the continuous shifting, combining, and transforming of materials, time, space, and participation of children, families, and educators produces assemblages full of potentiality for curriculum meaning making.

We draw on a story of educator meaning making that emerged early in the process of animating the newly created framework as an opportunity for deeper reflection on the co-inquiry processes, practices, and tools that support curriculum meaning making in action. We work with the understanding that curriculum in early childhood is socially co-constructed with children, families, and educators and that this process of making meaning is messy, iterative, deeply theoretical, and informed by both individual and collective intuition.

\section{The value of professional learning that begins educators' everyday practice}

Through talking, thinking, listening, pausing, imagining possibilities, and reflecting on what is seen, individuals access the data of their own experience and contribute to knowledge generation. Given supported structural contexts, caring, thoughtful and knowledgeable collaborators can use stories of experience as the yeast of professional learning. (Fleet \& Patterson, 2009, p. 17)

According to Curtis, Lebo, Cividanes, and Carter (2013), professional learning in the early childhood field has been "dominated by short, fragmented one shot workshops on a variety of topics delivered by experts who offer strategies and techniques outside the context of the daily teaching and learning with children" (p. 13). Deb Curtis and her colleagues call this approach "drive through professional learning" ( p. 13, italics in original). Another perspective is added by Linda Mitchell and Pam Cubey (2003), who call for professional learning that is grounded in practice and provides opportunities for educators to:

- consider their own work as a starting point "investigating real life examples of pedagogy within their own settings" (p. xi)

- work on issues that can make a difference in their practice

- reflect critically on taken for granted practices, questioning, and challenging taken for granted practices in ways that encourage new insight and shifts in thinking

- consider multiple, diverse perspectives and theories through pedagogical dialogue about their work

- gain awareness of the value of their work.

Similar to the process of learning for young children, professional learning can be understood as "a process of meaning-making or theory building in relationship with others who are called on to listen to the theories" (Moss, 2013, p. 39). Inviting educators to explore and revisit ideas over time leads to what Alma Fleet and Catherine Patterson (2001) refer to as "professional empowerment through spirals of engagement" (p. 10). 


\section{The value of an outside voice in facilitating pedagogical dialogue}

Pedagogical dialogue (Rinaldi, 2006) requires “active, open, and sensitive listening" (Abramson, 2012, p. 154) that is enhanced through facilitation by a pedagogical leader. This role is described in various ways in the literature, including as an external or outside voice (Fleet \& Patterson, 2001), a facilitator (Abramson, 2012), and a critical friend (Curtis et al., 2013; Fleet \& Patterson, 2001). In Reggio Emilia, the role is played by the pedagogista. In this research, we have adopted the term pedagogical mentor.

Shareen Abramson (2012) describes a facilitator as a "coach, model and catalyst" (p. 154) who is interested in growing and learning along with the teachers; the facilitator's role is to lead a collaborative inquiry process, "doing action research with documentation," and creating a space where educators grow in their ability to "demonstrate an attitude of acceptance for divergent interpretations, raise new questions, and suggest alternative viewpoints regarding a child or situation" (p. 154). According to Arthur Costa and Bena Kallick (as cited in Curtis et al., 2013), a critical friend is "a trusted person who asks provocative questions, provides data to be examined through another lens, and offers critique of a person's work” (p. 19). Critical friends raise new questions that challenge or expand thinking and provide positive feedback in a process Curtis and her colleagues call "a dance of challenge and support" (p. 19).

\section{Engaging educators as researchers: Professional learning as teacher research}

Teacher research, or practitioner inquiry, is increasingly recognized as a valuable source of professional learning and a tool for educational change (Fleet, De Gioia, \& Patterson, 2016; Henderson, 2012; Patterson et al., 2013; Stremmel, 2007). Teacher research contributes to our understanding of teaching and learning in early childhood settings, improving the likelihood that educators' voices will be heard and respected (Hatch, 2012). Describing teacher research as "the engine of professional development," Henderson (2012) found that engaging teachers as researchers results in "immediate and specific strategies for action" and an increase in teachers' ability to "relate their findings with voice and confidence" and reflect critically on "emotional reactions and pedagogical intentions" (p. 2).

Teacher research is also described as a strategy for resisting the typical transmission mode of professional development. There is increasing understanding that a linear conception of professional development (individuals in isolation moving along a predetermined sequence of steps toward development) is overly simplistic and fails to prioritize socially constructed knowledge (Fleet \& Patterson, 2001). Barbara Henderson (2012) argues that "when early childhood teachers undertake teacher research as collaborative action at their sites, it changes the nature of professional development and shifts teachers' identities as professionals ... up-ending the way professional development is traditionally organized" (p. 1). Positioning the educator as a researcher can result in a "socially constructed space where professional development happens continually" (Henderson, 2012, p. 2). Further insight comes from Gunilla Dahlberg and Hillevi Lenz Taguchi's notion of the "investigative teacher" who has

a divided yet integrated professional responsibility, which partly has to do with joining in a dialogue and in communicative action with the child or the children's group, and partly has to do with a reflective and investigative attitude towards the child's working process and their own work. (as cited in Moss, 2013, p. 25).

In this paper and in our research, we emphasize the importance of children remaining at the forefront of teacher research. Children's voices are heard and made visible through their own words and gestures, photos, drawings, and other artifacts collected by teacher researchers. This rich data, in the form of documentation, reminds us that 
children are not just the subjects of the research, they are agentic participants and co-researchers (Makovichuk, Hewes, Lirette, \& Thomas, 2014). We encourage educators to investigate focused research questions arising from collaborative reflection on documentation. In this way, we strive to enact teacher research as participatory, democratic, and inclusive in nature (Henderson, Meier, Perry, \& Stremmel, 2012, p. 5).

\section{Pedagogical documentation as a starting point for curriculum meaning making}

There is growing recognition in the early childhood literature that narratives produced by teachers in the form of pedagogical documentation, learning stories, or pedagogical narratives are a productive material form of teacher research (Carr, 2001; Carr \& Lee, 2012; Henderson et al., 2012; Pacini-Ketchabaw, Nxumalo, Kocher, Elliot, \& Sanchez, 2015; Rinaldi, 2006). Pedagogical documentation is a recognized and viable tool for sustained collaborative and dialogic practice, a process, Alice Wong (2009) asserts, that "makes visible, legible and sharable traces of children's learning, which becomes tangible material that can be shared and interpreted by others" (p. 26). Multiple readings of pedagogical documentation make teachers aware of the partiality of their own theories, and can precipitate the kind of crisis that motivates change and creates openness to the unexpected and uncertain (Rinaldi, 2006, pp. 181-183).

Through critical reflection and intentional practice, pedagogical documentation creates openness to change, making it possible for educators to participate in generating new knowledge about practice. In the words of Dahlberg and Lenz Taguchi:

through documenting what the child does and what one as the teacher does together with the child, one can see an increase in consciousness about the consequences of their [teachers'] actions, and thereby also gain a basis for change and development in their own work. (as cited in Moss, 2013, p. 26)

Pedagogical narrations (Pacini-Ketchabaw et al., 2015) invite multiple views of the child, multiple voices, and multiple interpretations. According to Veronica Pacini-Ketchabaw and her colleagues (2015), educator stories can be "intimately connected to curriculum making" (p. 123) through a discourse of meaning making. The importance of an active, engaged educator who can accommodate diversity, complexity, and multiple perspectives is becoming increasingly evident. The discourse of meaning making encourages individual judgments and uncertainty and views consensus and unanimity as neither necessary nor desirable (Pacini-Ketchabaw et al., 2015). It requires that individuals draw on concrete experiences and make ethical, philosophical choices and judgments that involve critical, reflective thinking about pedagogies. In this research, we take up this notion of pedagogical documentation as a discourse of meaning making, a process that calls on us to contextualize everyday practices within a particular social location and time and to make meaning of our experiences in dialogue with others (Pacini-Ketchabaw et al., 2015, p. 123). We focus our efforts on educator research that intends to produce transformation, enabling early childhood educators to develop an understanding of themselves, their classrooms, and their practice through the act of reflective inquiry (Stremmel, 2007).

\section{Animating Play, Participation, and Possibilities in practice through collaborative (co)- inquiry}

John Dewey first introduced the notion of teaching as inquiry in 1933, believing that educators construct knowledge socially, "through inquiry, with the assistance of colleagues and faculty who help them refine and clarify their ideas about their learning and teaching experiences" (Abramson, 2012, p. 149). Processes of co-inquiry have proven effective as a source of professional learning and improving practice (Abramson, 2012). As a low cost and practical 
strategy, co-inquiry helps educators see the significance of their work, gaining fresh insights and further skill in articulating their practice and explaining their curriculum decisions (Abramson, 2012, p. 154). Participation in a co-inquiry process supported by a pedagogical mentor results in educators feeling more passionate about their work (Abramson, 2012, p. 156). Educator testimony from our research confirms that co-inquiry supported by pedagogical mentoring was often accompanied by educators' growing sense of pride in their daily work and feelings of being reaffirmed and reignited in their role. Educators felt that their work was more visible, and in turn, more valued by others.

Following the release of Play, Participation, and Possibilities in 2014, phases two and three focused on introducing co-inquiry processes (Perry et al., 2012) for animating the framework with the four programs that participated in its co-creation during phase one. Phase three expanded to include four additional child care programs in small communities in northern Alberta. The research team recruited ECE faculty from local colleges as onsite pedagogical mentors. The process of onsite pedagogical mentoring included regular weekly visits to observe and document educator practice for purposes of reflection and dialogue. Pedagogical mentors engaged individuals and teams of educators in planned and spontaneous pedagogical conversations about pedagogical documentation and curriculum meaning making, providing diverse entry points and opportunities to engage with the concepts, holistic goals, and dispositions to learn in the framework. They helped each program to host a professional community of learners event and a family event featuring their work with the framework. Pedagogical mentors came together monthly for pedagogical dialogue with one another and the research team, both in person and with the support of an online platform.

As the project unfolded, early childhood educators in leadership roles in several participating centres stepped forward, eager to take up the role of pedagogical mentoring. Inspired by Louise Thomas and Jocelyn Nuttall (2014), who remind us that educators will engage in active negotiation of this new subject position in multiple ways, we set out to leave the possibilities of this new position open. Hoping to explore the relationality and complexity of the role as the project progressed, we asked those who volunteered to play this role to "find their own way in" and to "walk alongside educators" as they explored the use of Play, Participation, and Possibilities in everyday practice.

\section{Stories as a provocation for curriculum meaning making}

Consistent with the notion that meaningful professional learning begins with educator practice, we quickly found that using sample narratives and learning stories (Carr, 2001; Carr \& Lee, 2012) contributed by participating educators was a provocation to deeper pedagogical conversations and a source of professional learning among all of the project participants. These "little stories" (Cotton \& Griffiths, 2007) of children's care, play, and learning in specific early childhood communities began to circulate widely. They sparked one-on-one conversations as well as team dialogue, and were used by the research team at conferences and professional learning events to open a space for multiple readings using the curriculum framework concepts, holistic goals, and dispositions to learn. The processes of "story living and telling, and reliving and retelling" (Henderson et al., 2012, p. 8) and revisiting pedagogical documentation served to bring educator decision making into focus for critical reflection.

The working model of co-inquiry shaping our research with educators is an investigative cycle that involves three intertwined, recurring, and overlapping dimensions of educator practice:

- Co-learning (observing and documenting) alongside children, families, and colleagues

- Co-researching (reflecting and interpreting) through making connections to the curriculum framework and external sources of knowledge and theory 
- Co-imagining possibilities for further experiences (planning and taking action) and engaging playfully with children.

The model, inspired by the work of Abramson (2012), is a flexible frame for emergent, organic, and nonlinear curriculum planning and meaning making. We draw on the notion of the "missing middle" in emergent curriculum planning (Stacey, 2009). Typically, educators observe for interests and plan next steps, often in the moment and without taking the time to reflect. Taking time to "muck about" in the middle has proven inspiring for researchers and educators alike. In this model, curriculum evolves from children's everyday experiences and relies on educators' skillful observation and close listening to what children are doing, or wanting to do. Educators are active, reflective, critical thinkers in this planning process. Figure 2 is a working model of the co-inquiry processes we are using to support curriculum meaning making with Play, Participation, and Possibilities.

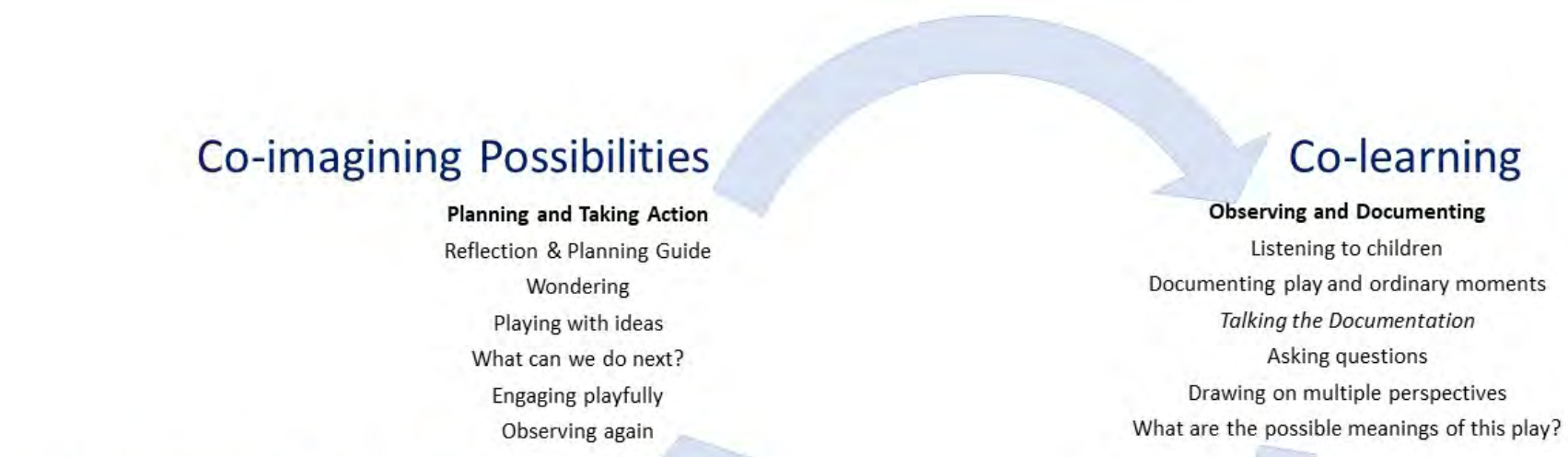

A Model of Co-Inquiry

for co-constructing curriculum

The "missing middle"

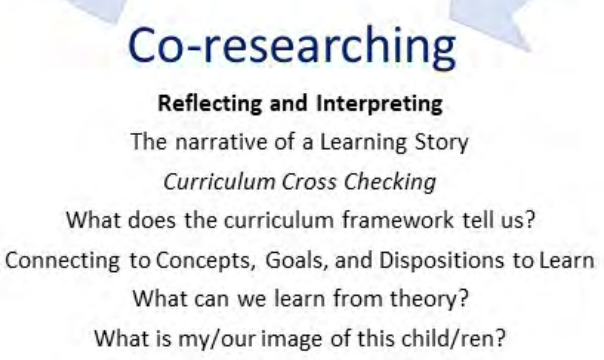

Figure 2. Co-inquiry: A working model.

As we engaged with educators in the co-inquiry process, we introduced two tools into the cycle to support curriculum meaning making: talking the documentation and curriculum cross-checking. Talking the documentation was shared with us by the research team at the University of New Brunswick and emerged from the co-creation of the New Brunswick Curriculum for Early Learning and Child Care (2008). Taking it up in our work with educators has supported participants to practice articulating and making visible their localized tacit knowledge of children's play and learning and to consider the diverse perspectives that others might bring to the conversation. Talking the documentation begins with educators' documented observations of children engaged with ideas, others, and materials. Revisiting these ordinary moments of children's active exploration in a collaborative dialogue with others provides a forum for thinking deeply, asking questions, and being tentative about reflections and interpretations. The goal of talking the documentation is to build a broad repertoire of possibilities-to expand our thinking 
about the range of possible meanings that this experience might have for children, as well as our theories about what meaning these experiences might have for children, what children might be doing, and what children might be wanting to do. Within the project, we explored talking the documentation in several ways, sometimes as an open, free-flowing process and often with the following set of guiding questions adapted from a reflective protocol developed by Project Zero at Harvard (see Cadwell, 2003) designed to structure dialogue about pedagogical documentation:

- What do you see?

- What questions does this play raise for you?

- What do you think the child (or children) is working on, trying to accomplish or communicate?

The second tool we used extensively in animating the curriculum framework with educators was curriculum crosschecking. Dorothy Strickland describes curriculum cross-checking as a strategy that allows children's "needs and interests to guide instruction and then uses the curriculum documents to reference particular goals, expectations or standards that have been met" (as cited in Heydon \& Iannacci, 2008, p. 166). In this project, we introduced curriculum cross-checking as a tool to interpret children's playing and learning in relationship to curriculum framework goals and dispositions. Curriculum cross-checking begins with educators' observations of children. It is a way for educators to draw on the curriculum goal descriptors to describe what they see the children doing using a common language. Curriculum becomes a living, evolving process that invites educators to think further about ways to extend and explore ideas, thoughts, and feelings. In Rachel Heydon and Luigi Iannacci's (2008) words, "cross-checking repositions curriculum as something co-created and negotiated ... whereby curriculum emerges from relationships rather than from requirements" ( p. 166).

\section{Beginning with tea}

Next, we offer a story, to borrow Iris Berger's (2010) words, "as an inspiration and a possibility to enlarge our shared thought and our shared understanding of what early childhood education is and what it can be about" (p. 72). As a source of participatory curriculum meaning making, the story affords multiple vantage points from which to view practice and children. Following Berger, we offer it not as a story of "best practice," but as an instance of how beginning with children as a source of curriculum inspiration in daily work can lead to practice transformation. As Berger reminds us, each story of children's actions "offers a possibility to meet a new child ... it affords a kind of listening that allows children to appear" (p. 71, italics in original).

This story took place early in the second phase of the research project in the Tanager Room in the MacEwan University Child Care Centre Lab School ${ }^{2}$, a community made up of 12 toddlers and their families and a team of three educators (Rebekah, Jennifer, and Bejuna). It involved the lab school educators, in particular Rebekah McCarron, and a member of the research team, Lee Makovichuk, who was acting as a faculty pedagogical mentor to the university child care educators. At the time, the centre had an established practice of pedagogical documentation and provided regular weekly time for educators to work on documentation, which tended to focus on creating portfolio entries for individual children. The curriculum framework research provided resources to support collaborative pedagogical dialogue, with regular opportunities for educators to step out of ratio and meet with Lee Makovichuk to revisit pedagogical documentation in relationship to curriculum framework goals and dispositions.

Engaging families in curriculum meaning making was a priority, and we were intentional about seeking their 
participation in creating the learning story samples during the development of the framework. By this time in the project, families in our lab school were familiar with the positive orientation of the learning story and looked forward to receiving stories about their child. Valuing the co-creation of the stories by educators, children, and families and the relationship between the learning story and the learner's identity (Carr \& Lee, 2012), we were reluctant to anonymize the stories. We received ethics approval to use children's first names and images in scholarly publications and professional learning events. Families' participation in making meaning of the stories was linked to their explicit consent and ensured that families, educators, and researchers alike were comfortable with the images, dialogue, and interpretations.

Choosing a starting point for a story is always difficult. We begin in early fall, just after the centre had been freshly painted. The empty walls provoked conversations about how children experienced the long, narrow hallway entrance into the centre. The centre director, educators, and faculty mentor began to talk about what they could do to set up points of interest for children coming and going. Thinking about the toddlers, they hung mirrors at the children's eye level and put a tea set on a small table under the director's office window as a provocation to see what children might do. The director had a perfect vantage point and became fascinated with watching the toddlers as they stopped to play on their way in and out of child care.

Meanwhile, the educators noticed pieces of the tea set were finding their way into the toddler room in the morning. Following conversation about how the children might be using play with the tea set as a transition into child care each day, the team decided to bring a tea set into the Tanager Room. Rebekah begins:

When we the brought the tea set into the room, we also brought in a small stove and set them up together by the sand box, and this was quickly noticed by children. Tea parties began happening soon after! Children all engaged in moments of pouring sand, also known as tea, into the small cups or into bowls.

The toddlers engaged immediately in sustained social pretend play. Lee noticed these interesting interactions, and the deep and rich play in the toddler room, when she came to observe. She saw these moments as rich in potential and as fertile ground for curriculum meaning making with children, but was unsure about whether the educators were noticing these moments or seeing them in the same way. She was finding it difficult to arrange to meet with this team of educators outside of the playroom to talk about the connections between their work and the curriculum framework.

\section{"We have to get to the diapering routine"}

Rebekah remembers:

As a new educator, my entry into the Tanager Room created a new team dynamic. Half of this group was new to the program in September. It took several months to feel as though we came together as a team and as a community with the children and families. Just as we began to feel this group cohesion, I recognized the weight I was feeling about the daily routines with toddler-age children. At the time, I felt that the efforts that we put into planning play and learning experiences seemed to get lost in the work of relationship building and routines.

Lee remembers inviting the team out to talk about what they were doing and hearing "we have to get to the diapering routine":

I spent a lot of time observing in that room. They spent time in the routines, they offered 
choices. They were in the moment with children in diapering, changing, getting ready for outside.

She would hear comments like "We get to meet today, I'm so excited" and then it wouldn't happen. Lee brought this dilemma to the research team. Together, we wondered if their hesitation was brought on by the intensity and weight of daily routines. Lee wondered how she could support them in conceptualizing the curriculum in the Tanager Room more holistically.

When the children were playing with the tea set, I was feeling that this team of educators were caught up in the daily routines. As much as the educators need to be in the room with the children, I wanted them to take a moment to really see what was happening, to make sense of what the children were doing. They were talking about routines in a different way than planning for play. I wanted them to see that what they were doing in routines was curriculum. That's when I said to myself, "we have to make this happen."

Following the conversation with the research team, Lee wondered if a conversation about the holistic goal of well-being, focused on providing "safe and caring environments where emotional and physical health, positive identities, and sense of belonging are nurtured and protected" (Makovichuk et al., 2014), would open a space for deeper discussion. She went to the centre director to ask for help in getting both Rebekah and Jennifer out of the room. Jennifer surprised Lee by arriving at the meeting with a video clip of the tea party play. As part of the co-inquiry process in curriculum meaning making, the educators in this room were using photos and video documentation to revisit ordinary moments of care, play, and learning for reflection and further planning. This short video became a provocation for co-inquiry over the next several weeks.

Lee writes:

I invited Rebekah and Jennifer to discuss their observations, their feelings, and the tensions between the importance of their daily work with children and the value of taking a step back to reflect. In a 30-minute meeting, we looked at the holistic goal, well-being, in Play, Participation, and Possibilities in relationship to Jennifer's video documentation of the children and the tea set. As we talked the documentation, and cross-checked with the goal, we discussed what the children might know and could do. It was an “Aha!" moment for the Tanager Room team!

\section{"What you were seeing changed and how you saw yourself in it changed"}

The opportunity to reflect and interpret with others using the common language of the curriculum framework produced new insights, and reenergized practice. As Lee describes it:

I could see a visible change in both Rebekah and Jennifer after the conversation, an excitement that I had not seen in months. I remember Jennifer saying that she knew curriculum was happening already.... I wondered what would transpire from this opportunity for them to revisit, reunderstand, what the children were doing in their play.

The educators began to talk about what they were seeing in relation to the goal descriptors (e.g., "children develop a sense of self, growing in their capacity to express feelings, concerns, and needs; children develop a sense of other, caring for others, [and] experiencing trust and compassion with children and adults" [Makovichuk et al., 2014, p. 94]). Rebekah writes:

Watching the video together, right away we noticed the children negotiating different roles and 
rules; the children were showing us their abilities to problem solve, work together, and share. Our observations led us to change one aspect of the lunch routine: we introduced communal serving bowls on the lunch table. We decided as a team that we would begin by serving each child a small portion, then place the communal food bowls in the centre of the table and see what unfolded.

This small shift in the lunch routine led to a big shift in thinking that resonates with the notion that collaborative reflection on documentation can produce change in practice. Rebekah recalls:

A story about Ainsley reveals just how mighty these children already are. It was the first day using the communal serving bowls. Upon hearing Noah ask for blueberries, Ainsley pulled the bowl of blueberries close to her. Jennifer momentarily paused, holding her breath, waiting, and wondering: Would Ainsley keep the berries for herself? Would she share the berries with Noah? In amazement, Jennifer watched as Ainsley reached all the way across the table, offering the bowl to Noah, saying, "Here blueberries!"

Later, Rebekah reflects:

This small change to the lunch routine has made a significant shift in how we think about our participation at lunch, from overseeing and serving, to modelling and supporting children's lunchtime interactions. The children's use of communication, team work, how they are developing awareness of one another's food likes and dislikes, and especially how much they already know about the social conventions of serving and sharing food with one another has really surprised me!

The connections to the framework deepened as educators found more and more language in the goal of wellbeing to describe and validate the significance of these small everyday experiences with young children. Rebekah continues:

We've also noticed children eating more food and staying at the lunch table longer. It has become a more communal and social time, an opportunity to share our stories and ideas together while also experiencing a sense of belonging. It has also opened avenues for communication with families as the educators are learning more about each family's social and cultural practices around sharing food.

\section{"It was already there, we just had to look at it through a different lens"}

As the educators continued to reflect on the goal of well-being, multiple possibilities for expanding and extending curriculum became visible to them. Rebekah adds:

After the initial excitement with the change in our lunch time I began wondering: What's next? Are they done with this, or is there another direction they want to go? I continued observing and documenting, but really took some time for reflecting. Through that reflection I started noticing shifts in myself as an educator. This change to our lunchtime routine has made me really slow down more during a busy transition time in our daily schedule. I have become much more aware of how much learning is happening during one of our most mundane daily tasks.

Through ongoing pedagogical conversations, revisiting documentation, further curriculum cross-checking, and more time spent reflecting and mucking about in the middle, the educators began to make multiple links between 
the concepts in Play, Participation, and Possibilities, their new lunchtime routine, and the environment, materials, and experiences they were selecting for the classroom.

Rebekah describes what happened next:

During the new lunch routine, Jennifer, Bejuna, and I recognized that the children were having some difficulty negotiating the larger serving spoons. We added spoons of all sizes and bowls into the sand area. One day I noticed Maude cooking. She had bowls of sand lined up and was taking sand from one to the other and mixing it together. "It's cake!" she said, as she took a pinch of sand from a third bowl. Later on that week, Selina and Stanley both made cookies from rocks and wood rings. Noah made some spaghetti with meatballs and zucchini using sand, ribbon, rocks, and wooden rings. The ideas of cooking, or preparing food, began to be very prominent during children's play in the sand box and kitchen.

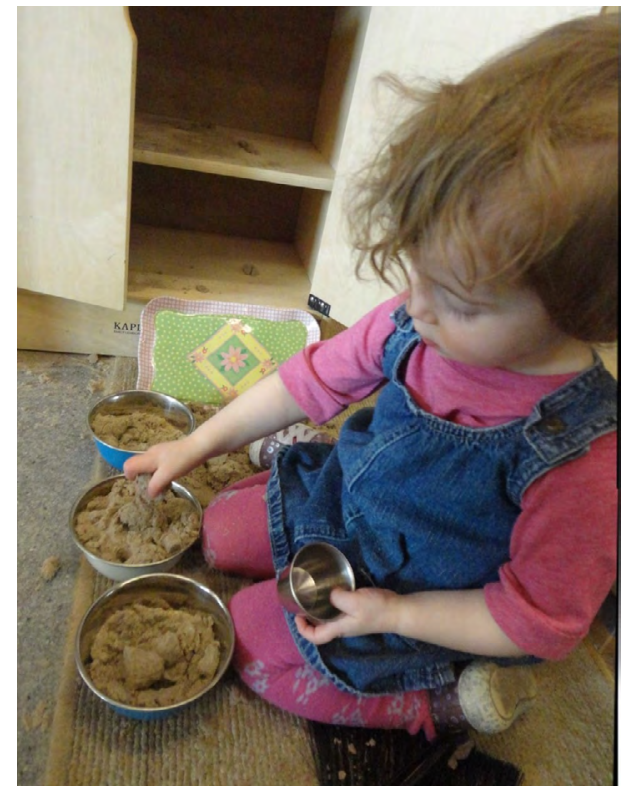

Figure 3. "It's cake!"

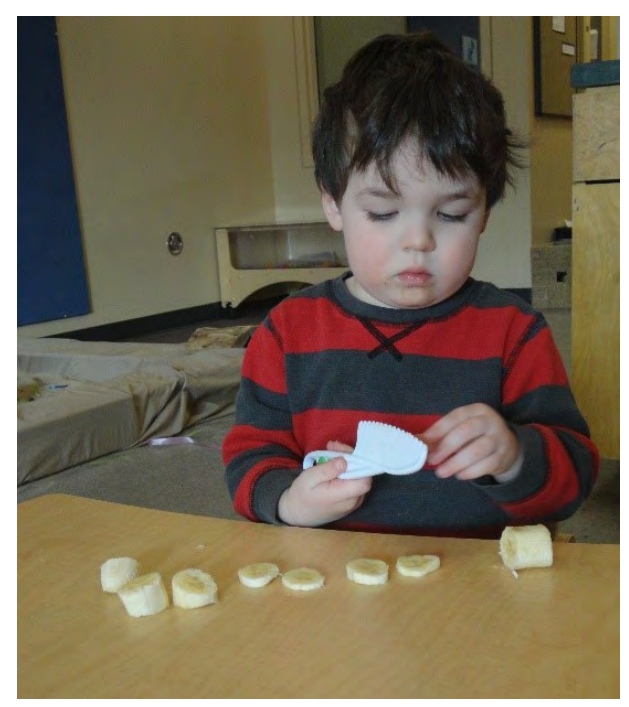

Figure 4. Cutting bananas.

\section{"I began seeing their family life in their play-I didn't see those connections before"}

The children's imaginary play with preparing, serving, and sharing food led naturally to experiences preparing real food. Rebekah describes how:

We started by cutting bananas for lunch. A group of us peeled, cut, and sliced bananas with plastic knives and then put them into a large bowl. After cleaning up, we put the big bowl of bananas with the rest of our lunch. While cutting the bananas we shared a conversation about how we all open and eat our bananas differently.

Experiences with real food opened further opportunities to communicate with families. Rebekah developed a new research question: "How do I work with families in the education and care of their children?" In pursuit of this question, and inspired by the well-being goal descriptor "Children learn about food and nutrition, exploring a range of cultural practices of eating and sharing food" (Makovichuk et al., 2014, p. 96), she actively sought out knowledge from the families about their social and cultural practices of preparing and sharing food. It became possible to open up conversations with families at the end of the day using anecdotes from their child's play (e.g., "I noticed your child pretending to drink tea at the sand table, do you do this at home?"). This led to planning for toddlers to participate in food shopping, as well as expanding the children's play through offering locally relevant cultural artifacts, such as chopsticks, and various types of tea sets. As an extension of this play, the educators and children prepared cookies and invited their families for a tea party.

\section{"I really didn't know I had anything to say"}

Rebekah was asked to share her story at several professional learning events. She continued to have pedagogical conversations with Lee as they progressed through a writing and rewriting process to prepare the story 
to be shared with other educators. Lee comments that "working through the story repeatedly meant revisiting our co-constructed meaning of the story to articulate what unfolded to others." Reflecting on the process and recognizing its partiality, Lee comments: "You can't pay attention to everything in the moment."

Rebekah reflects:

In my education, I have learned that I hold an image of the child, and that it should be-IS-a strong, resourceful, and capable child. But, what does that truly mean? Now in experiencing this notion, it has changed for me; my image of the child and what that means has deepened. The children surprise me every day with their

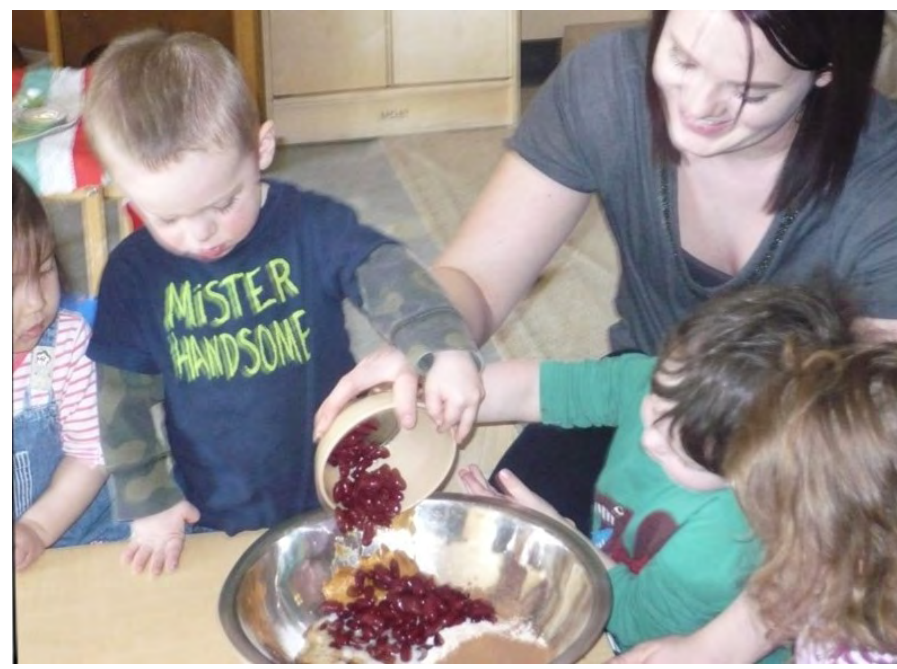

Figure 5. A tea party for families. capabilities to seemingly “act older than their age” when in truth, they aren't acting; they are simply being who they are. And they are amazingly capable beings as they communicate their ideas and feelings, as they care for one another and themselves, and as they explore with such focus and genuine interest.

As researchers, we noted the meaning of this experience for Rebekah's sense of professional identity and her ability to articulate practice. She continues:

While I noticed my evolving image of a child, I feel that I also experienced a major change in my image of myself, as an educator. I make many decisions each day. I make decisions in how I communicate my messages to children, the tone I use, the words I draw on to respect them as people in the room. When I chose new or familiar materials for the children's play and learning, these are decisions that communicate how I view them as learners and players. When children encounter problems and I offer them time and space and close observation, I communicate that I view them as strong, resourceful, and capable people, who sometimes need my help, or not. What I do does matter, and this realization has forever changed me.

Educator insights and reflection make visible some of the many ways possible to make meaning of this story, keeping curriculum alive and open (Pacini-Ketchabaw et al., 2015, p. 128). Lenz Taguchi (2007)reminds us that "in the very 'textualizing' of practice, it is, in fact, talked and written into existence-both as practice and as theoryand in that sense made accessible and even palpable, for being rewritten, retalked, and thereby re-performed and transformed" (p. 279). Retalking this story for this article once again foregrounds the educator's ability to observe, listen, question, and make connections that inform curriculum planning and change practice through the team's collaborative study of the documentation. Through her telling and retelling, Rebekah creates new meaningseeing herself beyond the metaphor of the "labourer" (Coulter \& Wiens 2002, as cited in Berger, 2010, p. 73) as a thinker, actor, and storyteller (Berger, 2010) - and embraces her life in the classroom as a co-learner, co-researcher, and co-imaginer of curriculum possibilities (Makovichuk et al., 2014).

\section{Closing}

Animating the use of a curriculum framework in everyday practice is not a "tick box" process. It is nonlinear, messy, 
iterative, deeply theoretical, and yet highly intuitive, drawing on local, situated knowledges and relationships. It is about living with curriculum as always already happening with/in the daily experiences of young children and their families in child care. It is not about "training" in specific competencies. Our preliminary findings suggest that this approach to curriculum requires an initial period of intensive, responsive, sustained pedagogical mentorship provided by well-educated, experienced mentors with expertise in early childhood pedagogy, as well as dedicated time for educators, outside of the playroom and also outside of their program setting, for dialogue and reflection with supportive pedagogical mentors, colleagues / team members, and the broader professional community. This process of pedagogical mentoring and co-inquiry led to productive reflection, concrete changes in practice, a growing sense of pride in daily work, and an enhanced sense of affirmation, valuing, and visibility of the work. The co-inquiry process has helped us to move beyond program planning to working with curricular resources informed by early learning pedagogies in a way that has the potential to transform practice and reinvigorate relationships.

We continue to explore how critical reflection on taken-for-granted notions of the image of the child and childhood, and our own work, has material results for daily practice and the ongoing social organization (Smith, 2005) of work with young children. Following Carla Rinaldi (2006, p. 184), we seek to better understand the conditions that invite dialogue with the power to transform practice and to set curriculum meaning making in motion. 


\section{Acknowledgments}

The authors thank the children, families, early childhood educators, and program directors at MacEwan Child Care Centre Lab School, Terra Child and Family Support Centre, Jasper Place Child and Family Resource Society, Child Development Dayhomes, and Intercultural Child and Family Centre, who contributed so generously to co-imagining new possibilities for animating curriculum in early learning and child care. We acknowledge our faculty colleagues and co-researchers - Nancy Thomas, Margaret Mykietyshyn, Rebecca Dupont, and Mary Lynne Matheson - for their thoughtful participation as pedagogical mentors. We are grateful for the support of Pam Whitty and the early childhood research team at the University of New Brunswick and for permission to use the goals from the New Brunswick Framework for Early Learning and Care in the Alberta framework.

\section{References}

Abramson, S. (2012). Co-inquiry: Documentation, communication, action. In G. Perry, B. Henderson, \& D. Meier (Eds.), Our inquiry, our practice: Undertaking, supporting, and learning from early childhood teacher research(ers) (pp. 147-157). Washington, DC: National Association for the Education of Young Children.

Bennett, J. (2004). Curriculum in early childhood education and care. UNESCO Policy Brief on Early Childhood. Retrieved from http:// unesdoc.unesco.org/images/0013/001374/137401e.pdf

Berger, I. (2010). Extending the notion of pedagogical narration through Hannah Arendt's political thought. In V. Pacini-Ketchabaw (Ed.), Flows, rhythms, \& intensities of early childhood education curriculum (pp. 57-76). New York, NY: Peter Lang.

Cadwell, L. (2003). Bringing learning to life: The Reggio approach to early childhood education. New York, NY: Teachers College Press.

Carr, M. (2001). Assessment in early childhood settings: Learning stories. London, UK: SAGE.

Carr, M., \& Lee, W. (2012). Learning stories: Constructing learner identities in early education. London, UK: SAGE.

Cotton, T., \& Griffiths, M. (2007). Action research, stories, and practical philosophy. Educational Action Research, 15(4), 545-560. doi: 10.1080/09650790701

Curtis, D., Lebo, D., Cividanes, W. C. M., \& Carter, M. (2013). Reflecting in communities of practice: A workbook for early childhood educators. St. Paul, MN: Redleaf.

Early Childhood Research Team, University of New Brunswick. (2008). New Brunswick curriculum framework for early learning and child care English. Retrieved from http://www2.gnb.ca/content/gnb/en/departments/education/elcc/content/curriculum/ curriculum_framework.html

Edwards, S., \& Nuttall, J. (Eds.). (2009). Professional learning in early childhood settings. Rotterdam, The Netherlands: Sense.

Eurofound. (2015). Working conditions, training of early childhood care workers, and quality of services: A systematic review. Retrieved from https://www.eurofound.europa.eu/publications/report/2015/working-conditions-social-policies/early-childhood-careworking-conditions-training-and-quality-of-services-a-systematic-review

Fleet, A., De Gioia, K., \& Patterson, C. (2016). Engaging with educational change: Voices of practitioner inquiry. London, UK: Bloomsbury.

Fleet, A., \& Patterson, C. (2001). Professional growth reconceptualized: Early childhood staff searching for meaning. Early Childhood Research and Practice, 3(2), 7-19.

Fleet, A., \& Patterson, C. (2009). A timescape: Personal narratives, professional spaces. In S. Edwards \& J. Nuttall (Eds.), Professional learning in early childhood settings (pp. 9-25). Rotterdam, The Netherlands: Sense.

Hatch, A. (2012). Teacher research: Questions for teacher educators. In G. Perry, B. Henderson, \& D. Meier (Eds.), Our inquiry, our practice: Undertaking, supporting, and learning from early childhood teacher research(ers) (pp. 117-125). Washington, DC: National Association for the Education of Young Children. 
Henderson, B. (2012). Teacher research: Effects on professional development and professional identity. Voices of Practitioners, 7(1), 1-6.

Henderson, B., Meier, D. R., Perry, G., \& Stremmel, A. J. (2012). The nature of teacher research. In G. Perry, B. Henderson, \& D. Meier (Eds.), Our inquiry, our practice: Undertaking, supporting, and learning from early childhood teacher research(ers) (pp. 3-10). Washington, DC: National Association for the Education of Young Children.

Heydon, R. M., \& Iannacci, L. (2008). Early childhood curricula and the de-pathologizing of childhood. Toronto, ON: University of Toronto Press.

Lenz Taguchi, H. (2007). Deconstructing and transgressing the theory-practice dichotomy in early childhood education. Educational Philosophy and Theory, 39(3), 275-290.

MacNaughton, G., \& Hughes, P. (2008). Doing action research in early childhood studies: A step by step guide. Maidenhead, UK: Open University Press/McGraw Hill Education.

Makovichuk, L., Hewes, J., Lirette, T., \& Thomas, N. (2014). Play, participation, and possibilities: An early learning and child care curriculum framework for Alberta. Retrieved from http://childcareframework.com/

Mitchell, L., \& Cubey, P. (2003). Characteristics of professional development linked to enhanced pedagogy and children's learning in early childhood settings: Best evidence synthesis. Wellington NZ: Government of New Zealand Ministry of Education.

Moss, P. (Ed.) (2013). Early childhood and compulsory education: Reconceptualising the relationship. Abingdon, UK: Routledge.

Olsson, L. M. (2009). Movement and experimentation in young children's learning: Deleuze and Guattari in early childhood education. London, UK: Routledge.

Pacini-Ketchabaw, V., Kocher, L., Sanchez, A., \& Chan, K. (2009). Rhizomatic stories of immanent becomings and intra-activity: Professional development reconceptualized. In L. Iannacci \& P. Whitty (Eds.), Early childhood curricula: Reconceptualist perspectives. Calgary, AB: Detselig.

Pacini-Ketchabaw, V., Nxumalo, F., Kocher, L., Elliot, E., \& Sanchez, A. (2015). Journeys: Reconceptualizing early childhood practices through pedagogical narration. Toronto, ON: University of Toronto Press.

Patterson, C., McAuley, E., \& Fleet, A. (2013). Leading change from the inside: A braided portrait. Reflective Practice, 14(1), 58-74. doi: $10.1080 / 14623943.2012 .732938$

Perry, G., Henderson, B., \& Meier, D. (Eds.). (2012). Our inquiry, our practice: Undertaking, supporting, and learning from early childhood teacher research(ers). Washington, DC: National Association for the Education of Young Children.

Rinaldi, C. (2006). In dialogue with Reggio Emilia: Listening, researching, and learning. New York, NY: Routledge.

Sellers, M. (2013). Young children becoming curriculum: Deleuze, Te Whariki, and curricular understandings. Abingdon, UK: Routledge.

Smith, D. (2005). Institutional ethnography: A sociology for the people. Lanham, MD: Altamira.

Stacey, S. (2009). Emergent curriculum in early childhood settings: From theory to practice. Curriculum in action. St. Paul, MN: Redleaf.

Stremmel, A. J. (2007). The value of teacher research: Nurturing professional and personal growth through inquiry. Voices of Practitioners, 2(3), $1-9$.

Thomas, L., \& Nuttall, J. (2014). Negotiating policy-driven and state-mandated expectations of leadership: Discourses accessed by early childhood educators in Australia. New Zealand Research in Early Childhood Education Journal, 17, 101-114.

Wong, A. C. Y. (2009). Dialogue engagements: Professional development using pedagogical documentation. Canadian Children, 34(2), 25-30. 


\section{(Endnotes)}

In June 2018, Play, Participation, and Possibilities: An Early Learning and Child Care Framework for Alberta was renamed Flight: Alberta's Early Learning and Care Framework.

2 In 2017, the MacEwan University Child Care Centre Lab School was renamed Early Learning at MacEwan (ELM). 